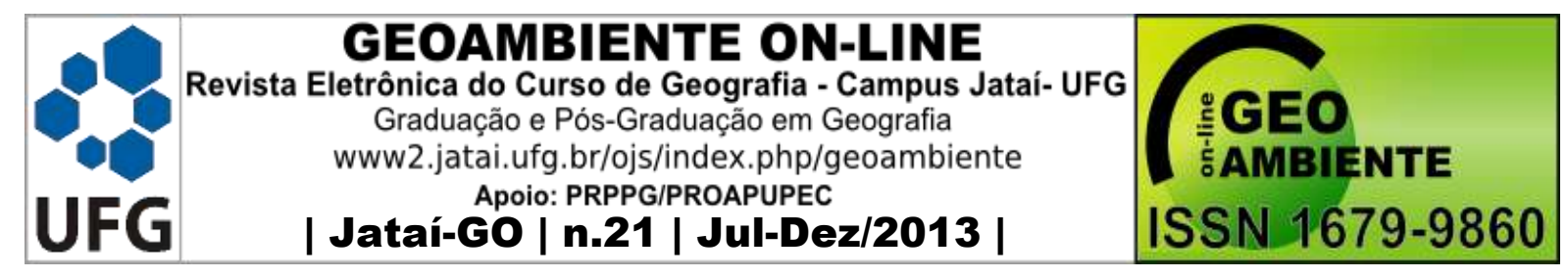

\title{
O CONCEITO DE MEIO TÉCNICO EM MILTON SANTOS ${ }^{1}$
}

\section{Carlos Francisco Gerencsez Geraldino}

Universidade Estadual de Campinas, Doutorando em Geografia pelo Instituto de Geociências da UNICAMP, bolsista da Fundação de Amparo à Pesquisa do Estado de São Paulo FAPESP. E-mail: carlosgeraldino@gmail.com. Rua João Pandiá Calógeras 51, Campinas-SP, CEP: $13083-870$.

\section{Resumo}

Este artigo tem como objetivo expor sinteticamente o entendimento do conceito de meio vinculado ao fenômeno técnico proposto pelo geógrafo brasileiro Milton Santos. Para isso, primeiro se discute o conteúdo que propôs aos conceitos de meio, técnica, natureza e espaço, procurando entrever suas relações. Depois, se apresenta sua proposta gradual de análise da transformação do meio natural em meio técnico-científico e informacional, pontuando os recortes conceituais utilizados em cada etapa do processo de artificialização do entorno. Para, por fim, demonstrar como os conteúdos técnicos agregados ao meio geográfico podem fazê-lo revelar-se como um atuante ente social; legitimando, dessa maneira, a análise geográfica como uma das principais vias de compreensão das relações sociais contemporâneas.

Palavras-chave: meio técnico; conceito; Milton Santos; geografia; epistemologia.

\section{Abstract}

\section{THE CONCEPT OF TECHNICAL ENVIRONMENT IN MILTON SANTOS}

This article aims to explain briefly the understanding of the concept of environment linked to the technical phenomenon proposed by Brazilian geographer Milton Santos. For this, first discusses the content that proposed the concepts of medium, technique, nature and space, trying to observe their relationships. Then, it presents its proposal gradual analysis of the transformation of the natural environment in technical-scientific and informational environment, punctuating the cutouts conceptual used in each stage of the artificiality of the surroundings. To finally demonstrate how the technical content added to the geographical

\footnotetext{
Artigo recebido para publicação em 05 de Junho de 2013

Artigo aprovado para publicação em 04 de Outubro de 2013

${ }^{1}$ Texto baseado em parte dos resultados da pesquisa de mestrado intitulada $O$ conceito de meio na geografia (2010) defendida junto ao Programa de Pós-Graduação em Geografia Humana da Universidade de São Paulo.
} 


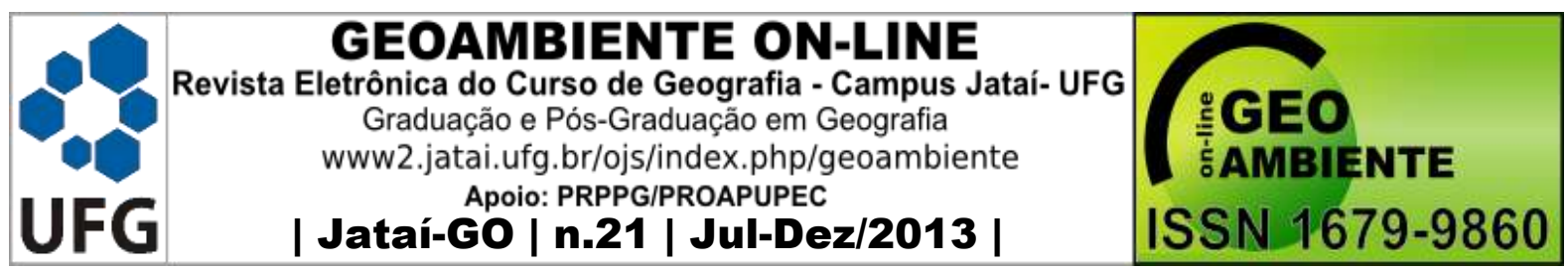

environment can make it reveal itself as an active social being; legitimizing therefore the geographical analysis as a key way of understanding contemporary social relations.

Key words: technical environment; concept; Milton Santos; geography; epistemology.

\section{Resumen}

\section{EL CONCEPTO DE MEDIO TÉCNICO EN MILTON SANTOS}

Este artículo pretende explicar brevemente la comprensión del concepto de medio vinculado a fenómeno técnico propuesto por el geógrafo brasileño Milton Santos. Para ello, primero se analiza el contenido que propuso el concepto de medio, la técnica, la naturaleza y el espacio, tratando de observar sus relaciones. Después, se presenta la propuesta de analizar la transformación gradual del medio natural en el medio técnico-científico e informacional, puntuando los recortes conceptuales utilizados en cada etapa de la artificialidad de los alrededores. Para demostrar finalmente, cómo el contenido técnico añadió al medio geográfico puede resultar esto como un ser social activo; legitimando, así, la análisis geográfica como uno dos principales caminos de entendimiento de las relaciones sociales contemporáneas.

Palabras clave: medio técnico, concepto; Milton Santos; geografía, epistemología.

\section{Introdução}

A interpretação do conceito de meio vinculado ao fenômeno técnico não é algo que se faz recente no cenário epistemológico da geografia acadêmica. Nomes como Paul Vidal de La Blache, Albert Demangeon, Max. Sorre ${ }^{2}$, Jean Gottman, Pierre Gourou, Pierre George e Jean Labasse; debruçaram-se sobre o tema e contribuíram, cada qual com a sua ótica, decisivamente ao enriquecimento teórico desse vínculo (SANTOS, 2004). Contudo, se, restringindo o campo de análise, focarmos a atenção apenas ao cenário contemporâneo da geografia acadêmica brasileira, logo veremos que jamais conseguiremos discorrer por mais de uma página sobre o conceito de meio técnico sem mencionar um nome em específico, esse nome, como sabemos, é o de Milton Santos. Dificilmente encontraremos algum geógrafo que atualmente pesquise aspectos da realidade utilizando-se de conceitos como técnica ou de meio técnico sem a ele fazer referência. Isso se deve ao tamanho da sua influência acadêmica

\footnotetext{
${ }^{2}$ Max. Sorre, segundo Milton Santos, foi “[...] o primeiro geógrafo a propor, com detalhe, a consideração do fenômeno técnico, em toda sua amplitude" (2004, p. 35).
} 


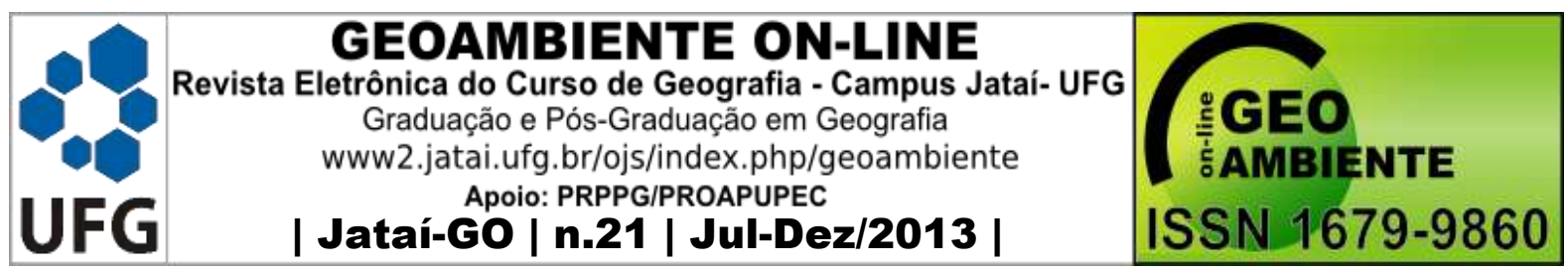

derivada de seus esforços, não isolados, na busca de compreender as intrincadas relações entre geografia e a técnica. Assim, se queremos entender o sentido de uma facetas com as quais o conceito de meio hoje se apresenta, no caso o meio como meio técnico, necessariamente teremos que nos debruçar na obra deixada por esse autor. Porém, estudar e descrever seu sistema conceitual como um todo extrapolaria em muito os objetivos desse artigo. Dessa maneira, cabe esclarecer que aqui o entendimento de seu sistema conceitual, e em particular de sua concepção de técnica, não visa outra coisa senão sua direta relação à compreensão do conceito de meio.

O que se segue, portanto, é uma análise sintética do conceito de meio proposto por Milton Santos sob o viés da técnica. Assim, primeiramente se discute o conteúdo que propôs aos conceitos de meio, técnica, natureza e espaço, procurando entrever suas relações. Depois, apresenta-se a gradual transformação do meio natural em meio técnico-científico e informacional, pontuando os recortes conceituais utilizados pelo autor em cada etapa do processo de artificialização do entorno. Para, por fim, demonstrar como os conteúdos técnicos agregados ao meio podem fazê-lo agir como ente social; legitimando, dessa forma, a análise geográfica como uma das principais vias reveladoras da sociedade contemporânea.

\section{Do meio técnico ao meio técnico-científico informacional}

Se, em 1978, Milton Santos expunha sua insatisfação acerca do trato ao qual vinha sendo dado ao conceito de meio asseverando que "[...] dificilmente os geógrafos podem reclamar de outros especialistas o uso que fazem de palavras como 'meio geográfico', 'meio físico', 'meio natural', ou simplesmente 'meio', pois entre os geógrafos, a ambiguidade é a regra geral" (p. 21). Por sua vez, quase duas décadas mais tarde, após uma sucessão de ensaios, livros e artigos, apresenta detalhadamente uma sistematização ampla de suas ideias na obra A natureza do espaço (cuja primeira edição data de 1996), onde o conceito de meio, além de afigurar-se como peça-chave na trama conceitual, aparece metodicamente atrelado a outros conceitos como a técnica, a ciência e a informação ${ }^{3}$. Já no início do primeiro capítulo desta obra podemos ver com clareza o caminho teórico que se concentrará; lá, Santos expõe que:

\footnotetext{
${ }^{3}$ Segundo Flávia Grimm (2009), a expressão meio técnico-científico aparece pela primeira vez nos escritos de Milton Santos no ano de 1981, para somente após mais de uma década ser modificada, ou melhor, ser acrescentada de mais um termo: informacional. Apresentando, portanto, como meio técnico-científico e informacional.
} 


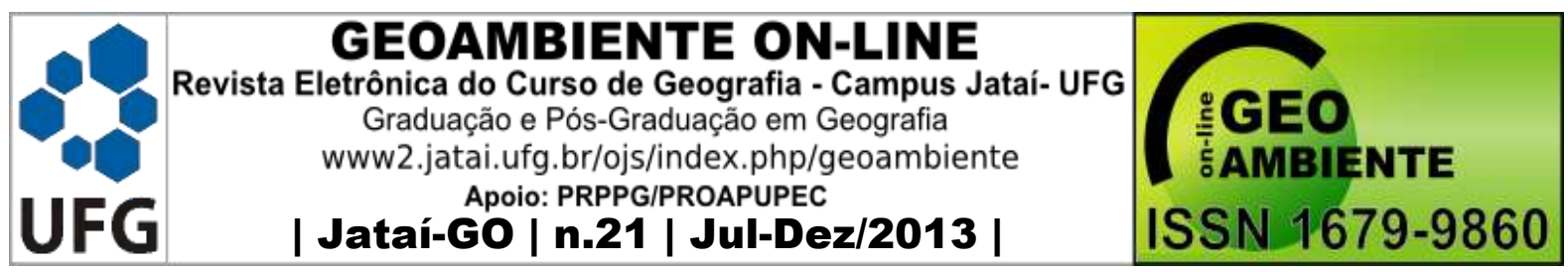

É por demais sabido que a principal forma de relação entre o homem e a natureza, ou melhor, entre o homem e o meio, é dada pela técnica. As técnicas são um conjunto de meios instrumentais e sociais, com os quais o homem realiza sua vida, produz e, ao mesmo tempo, cria espaço. Essa forma de ver a técnica não é, todavia, completamente explorada (2004, p. 29).

Nesta passagem, vários elementos já estão postos. O primeiro, e mais evidente, é a escolha teórico-metodológica feita querendo entender as recíprocas relações entre a sociedade e a natureza pelo viés da técnica. Ou seja, o autor deixa por entrever que existem outros tipos de relação para este binômio, porém, afirmando ser a técnica a principal, opta por ela. Um segundo, não menos evidente, é a atribuição dual de sentido ao conceito de meio. Isso, pois, se num primeiro momento o termo meio aparece como aquilo que envolve o homem, ou seja, sendo o outro do homem, sua alteridade, seu entorno - o que, por conseguinte, permite a relação -, num segundo momento, o termo meio aparece na própria definição do que é técnica, como sinônimo de recurso. Assim, mesmo nesta pequena e introdutória passagem já se pode identificar, e no transcorrer do texto se confirmar, a dupla designação em que o termo meio é entendido pelo autor: como entorno e como recurso. Já os outros elementos, apesar de estarem presentes na passagem, não estão tão evidenciados como estes primeiros, abrigandose no transcorrer do texto. Estes dizem respeito ao significado dos conceitos de natureza, meio, técnica e espaço, como também de suas interelações.

Atentemos primeiro à relação entre natureza e meio. Aquele que iniciando a leitura desta obra depara-se com o trecho já aqui citado: “[...] a principal forma de relação entre o homem e a natureza, ou melhor, entre o homem e o meio [...]" (grifo nosso), pode, com razão, indagar sobre o que o autor entende por meio e por natureza. Seriam eles termos sinônimos? No decorrer da leitura verá que sim. Apesar de não haver particular preocupação em definir o conceito de natureza, Santos, em vários momentos, considera que a partir do momento em que existe o homem, seu olhar para o entorno natural é dirigido à apreensão prática e simbólica, transformando de imediato a natureza em recurso para suprir sua sobrevivência. Essa apreensão do meio, ou da natureza, é feita pela técnica. Santos chega mesmo a levantar a pergunta se haveria uma distinção entre o que é natural e o que é artificial do meio. Porém, apressa-se em responder que "[...] para os fins de nossa análise, mesmo os objetos naturais poderiam ser incluídos entre os objetos técnicos, se é considerado o critério de uso possível" (2004, p. 38). Assim, mesmo os objetos provenientes de processos naturais seriam interpretados, pelo "critério do uso possível", como tendo potenciais finalidades ao homem e, 


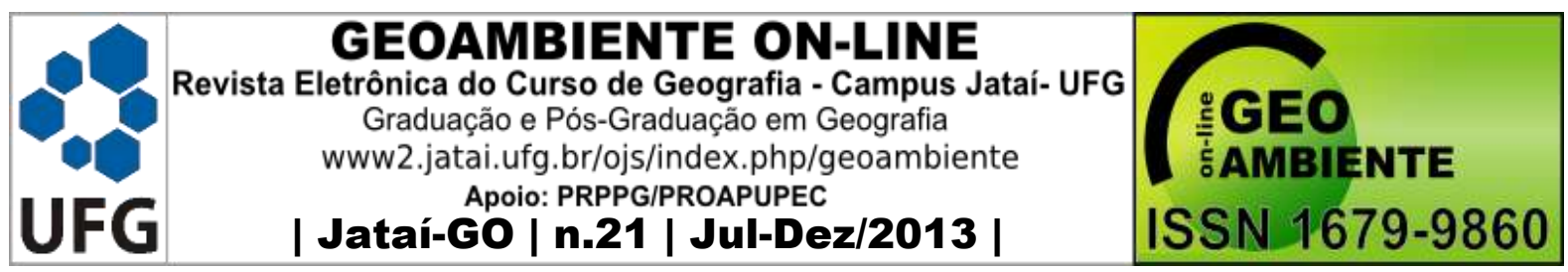

portanto, poderiam ser considerados como meios. Daí, a técnica, segundo o autor, seria uma possível resolução de certa má herança da Geografia de considerar homem e natureza como fenômenos separados.

Se o entendimento da relação entre os conceitos de meio e de natureza em Santos são pautados pela técnica, faz necessário sabermos então qual é a relação entre meio e técnica. $\mathrm{E}$ esta, não muito diferente da anterior, resulta numa quase paridade dos conteúdos dos termos. Como é expresso em um dos subtítulos de A natureza do espaço: "A técnica, ela própria, é um meio" (ibidem). Dessa maneira, aquilo que envolve o homem, sua geografia, seu meio, é composto de tecnicidade. O olhar então estaria sempre procurando finalidades, por isso, enxergando tudo ao seu redor como meio; mesmo aqueles objetos, como vimos, de origem natural. A geografia faz-se, dessa feita, como o resultado histórico de um processo de tecnificação que o homem faz de seu meio. Pois, como aferiu Santos, referenciando Nathan Rotenstreich, "[...] a própria história se torna um meio (um environment)" (ibidem, p. 40). Sendo o meio geográfico o mesmo que meio técnico. Daí, em suas próprias palavras, vemos que:

[...] não há essa coisa de um meio geográfico de um lado e de um meio técnico do outro. O que sempre se criou a partir da fusão é um meio geográfico, um meio que viveu milênios como meio natural ou pré-técnico, um meio ao qual se chamou de meio técnico ou maquínico durante dois a três séculos, e que hoje estamos propondo considerar como meio técnico-científico-informacional (ibidem, p. 41).

Ou seja, o meio geográfico é constante resultado nunca acabado da técnica em desenvolvimento. Porém, antes de nos debruçarmos na análise desses novos elementos (o científico e o informacional) do meio atual, devemos ainda resolver a última relação exposta em questão na primeira passagem, a relação entre o conceito de meio e o de espaço.

Numa pergunta, meio e espaço, para Milton Santos, também são termos correlatos? Considerando esta frase do próprio: "É por isso que estamos considerando o espaço geográfico do mundo atual como um meio técnico-científico-informacional" (ibidem, p. 240), necessariamente teremos que responder de forma afirmativa. Esta é a passagem que mais evidencia a semelhança entre estes termos, mas em vários momentos das suas obras isso fica subsumido. Espaço é demonstrado por Milton Santos como algo diferençável de paisagem e configuração territorial ${ }^{4}$. Todavia, é possível se afirmar - dada, primeiro, a ausência da

\footnotetext{
${ }^{4}$ Como bem explicita nessa passagem: "Paisagem e espaço não são sinônimos. A paisagem é o conjunto de formas que, num dado momento, exprimem as heranças que representam as sucessivas relações localizadas entre
} 


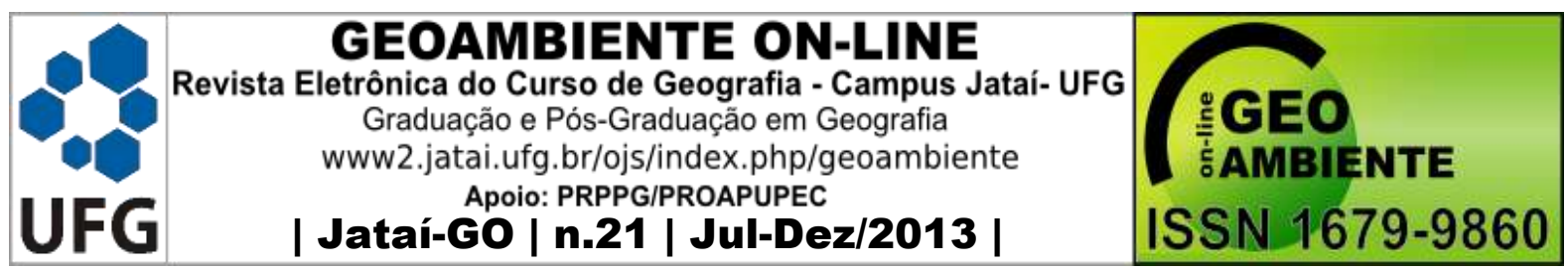

diferenciação em seus escritos e, segundo, pela simples substituição dos termos sem ressalvas em várias passagens de suas obras - que meio - ora expresso como meio técnico-científico e informacional (2004, p. 41), como meio geográfico (idem), como meio social ambiente (1999, p. 17), como meio ambiente (2003, p. 7) ou como meio ambiente construído (1998, p. 73) - e espaço são termos equivalentes, portanto, sinônimos.

Autorizados por esse raciocínio, talvez não estivéssemos exagerando se interpretássemos o título de seu principal livro como A natureza do meio. Afinal, o espaço é composto pelas formas territorializadas mais a sociedade que as anima - ou seja, por objetos e ações - e o meio - entendido pelo autor como entorno e recurso, sendo relativo à existência de algum indivíduo ou da sociedade - é, então, também composto de formas territoriais e sociedade propiciadora de dinâmica. E ainda mais, ambos, meio e espaço, existiriam tanto objetivamente quanto subjetivamente. Caso que a seguir pode-se evidenciar na precisão e na sobreposição não conflitiva que o autor faz no uso desses termos:

\begin{abstract}
O espaço se impõe através das condições que ele oferece para a produção, para a circulação, para a residência, para a comunicação, para o exercício da política, para o exercício das crenças, para o lazer e como condição de "viver bem". Como meio operacional, presta-se a uma avaliação objetiva e como meio percebido está subordinado a uma avaliação subjetiva. Mas o mesmo espaço pode ser visto como terreno das operações individuais e coletivas, ou como realidade percebida. $\mathrm{Na}$ realidade, o que há são invasões recíprocas entre o operacional e o percebido. Ambos têm a técnica como origem e por essa via nossa avaliação acaba por ser uma síntese entre objetivo e o subjetivo (SANTOS, 2004, p. 55, grifo nosso).
\end{abstract}

A subjetividade e objetividade relacionadas ao meio expressas na passagem têm, para Santos, nomes próprios, respectivamente: psicoesfera e tecnoesfera. Sendo ambas “[...] redutíveis uma à outra" (ibidem, p. 256). A tecnoesfera responde pela materialidade do meio. É o resultado nunca acabado dos processos de territorialização das técnicas, fazendo-se como próteses aderidas ao meio natural. Já a psicoesfera é a parte subjetivada do meio. São as ideias amalgamadas à expansiva artificialização do meio. Em um exemplo utilizando-se do território nacional (1998, p. 32), Santos clarifica estes termos ao dizer que a tecnoesfera dá-se como fenômeno contínuo na maior parte do Sul e do Sudeste brasileiro, chegando até quase a cobrir o Mato Grosso do Sul, já a psicoesfera apresenta-se como uma realidade em todo país. Ou

homem e natureza. O espaço são essas formas mais a vida que as anima. A palavra paisagem é frequentemente utilizada em vez da expressão configuração territorial. Esta é o conjunto de elementos naturais e artificiais que fisicamente caracterizam uma área. A rigor, a paisagem é apenas a porção da configuração territorial que é possível abarcar com a visão. Assim, quando se fala em paisagem, há, também, referência à configuração territorial e, em muitos idiomas, o uso das duas expressões é indiferente" (SANTOS, 2004, p. 103). 


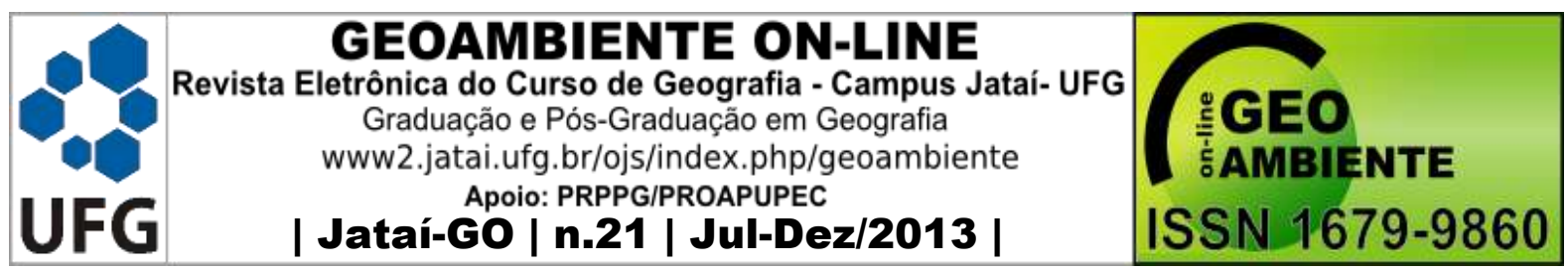

seja, mesmo naqueles lugares onde não há uma tecnificação expressiva do território já pode haver alguns comportamentos e desejos, gerados e perpassados pelos meios de comunicação, de regiões altamente tecnificadas. Todavia, psicoesfera e tecnoesfera são aspectos atuais de uma única e mesma realidade: o meio técnico-científico-informacional. E somente o entendimento dessa composição terminológica possibilitará uma melhor compreensão do conceito de meio utilizado pelo autor.

A transformação do meio natural no meio técnico-científico-informacional se dá por etapas de artificialização do entorno. Como talvez se poderia imaginar a princípio, a noção de meio natural não se faz aquela apenas proveniente de um território sem humanos. É possível haver humanos habitando e modificando certa porção do território sem, no entanto, este ser classificado por Santos como meio técnico. Para o autor, o meio natural só passa a ser um meio técnico com a invenção das máquinas. Isso é passível de ser verificado em suas palavras, ao afirmar que: "Estamos porém, reservando a apelação de meio técnico à fase posterior à invenção e ao uso das máquinas, já que estas, unidas ao solo, dão uma nova dimensão à respectiva geografia" (2004, p. 234). Assim, a máquina seria um recorte teórico derivado do entendimento de que seu surgimento alterou significativamente as relações entre sociedade e natureza proporcionando - com a territorialização em formas de estradas de ferro, rodovias, fábricas etc. - uma nova configuração geográfica no mundo. E a consonância com a natureza rompida dá a luz ao um novo meio, o meio técnico.

Milton Santos enfatiza que a relação do homem com a natureza é sempre mediada pela técnica. E, seguindo tal raciocínio, para qualquer ato humano, em um determinado meio, já teríamos que chamá-lo de meio técnico. Pois, uma abertura na floresta ou construções de abrigos feitos com materiais encontrados na natureza e pouco modificados seriam, sem dúvida, frutos de sistemas técnicos. Porém, Santos argumenta que nessas condições de vida nestes "gêneros de vida", para lembrarmos a clássica designação de Paul Vidal de La Blache (1946) - é presente uma ligação harmônica entre homem e meio; e que mesmo este meio sendo produto de certas modificações, estas, por contrapartida, não seriam tão agressivas, a ponto mesmo de ainda podermos chamá-lo de meio natural. Haveria, assim, nestes espaços ou meios a presença de "[...] sistemas técnicos sem objetos técnicos" (SANTOS, 2004, p. 236). Já o meio técnico conteria objetos resultantes não só de processos estritamente culturais, mas também de objetos puramente técnicos; estes, no sentido de serem produtos de cálculos racionais que não necessariamente estivessem relacionados aos ditames tradicionais daquele 


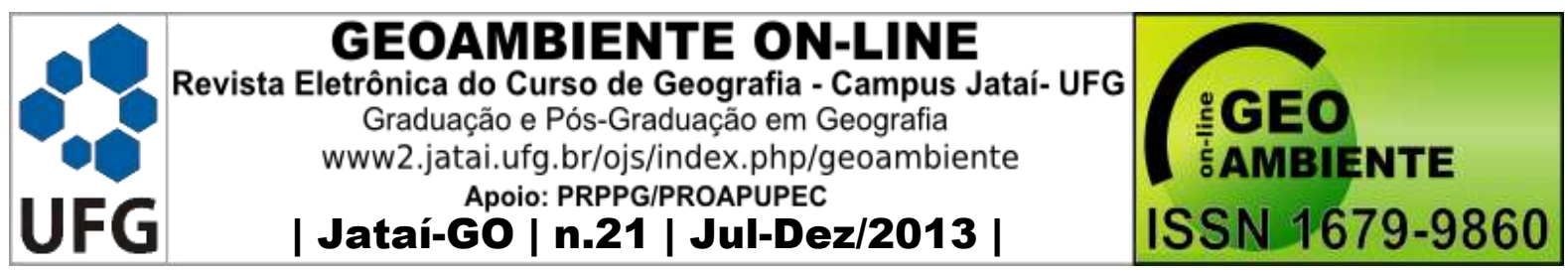

grupo humano. Inaugurando, assim, na história da humanidade, um estranhamento do entorno derivado não mais pela não compreensão dos processos naturais, mas, sim, pelo novo meio resultante dos próprios objetos artificiais.

Para ressaltar esse raciocínio, Santos nos lembra de que fomos “[...] rodeados, nestes últimos quarenta anos, por mais objetos do que nos precedentes quarenta mil anos" (1998, p. 21). E, de tal modo, os raciocínios referentes aos porquês das coisas estarem onde estão portando, raciocínios eminentemente do tipo geográfico - já não podem ser realizados tendo unicamente a cultura local como referência. O meio técnico é produzido tendo outros ditames, outra razão; "A razão do comércio, e não a da natureza, é que preside à sua instalação" (2004, p. 237), dizia. Razão vinda, muitas vezes, de outros lugares. Razão colonizadora, capitalista. Tornando o meio um híbrido cada vez menos fruto de uma ordem proveniente da cultura local para ser resultado de uma razão de tipo comercial. Sintetizando, expõe que:

\footnotetext{
Ontem, o homem se comunicava com o seu pedaço da natureza praticamente sem mediação, hoje, a própria definição do que é esse entorno, próximo ou distante, o Local ou o Mundo, é cheia de mistérios. Agora que todas as condições de vida, profundamente enraizadas, estão sendo destruídas (A. Wellmer, 1974), aumenta exponencialmente a tensão entre a cultura objetiva e a cultura subjetiva e, do mesmo modo, se multiplicam os equívocos de nossa percepção, de nossa definição e de nossa relação com o Meio (SANTOS, 1998, p. 22).
}

Data da década de 1970 um incremento científico ao meio técnico. Na verdade, ainda técnico, porém com técnicas inovadoras descobertas por processos acelerados em laboratórios. A ciência potencializou a técnica ao tratá-la como um fim em si próprio; inaugurando, assim, a tecnologia. Essa, por sua vez, é esparramada estrategicamente ao território azeitando ainda mais a tríade de produção, circulação e consumo de mercadorias. Todavia, o alargamento das fronteiras visando uma mais-valia de nível global não poderia vir senão acompanhadas de alguma espécie de controle. Controle tanto na sincronização da produção e circulação de mercadorias em fábricas distantes de suas sedes, quanto na garantia do consumo dessas. De maneira que tão logo que o meio técnico-científico se assentou já foi prontamente adicionado de um mundo de redes comunicacionais sob a forma de cabos submarinos, satélites e antenas, forjando o que hoje temos como a "cara geográfica" (idem, 2004, p. 239) do processo de globalização: o meio técnico-científico-informacional.

\section{Da análise do meio técnico à legibilidade da Geografia}




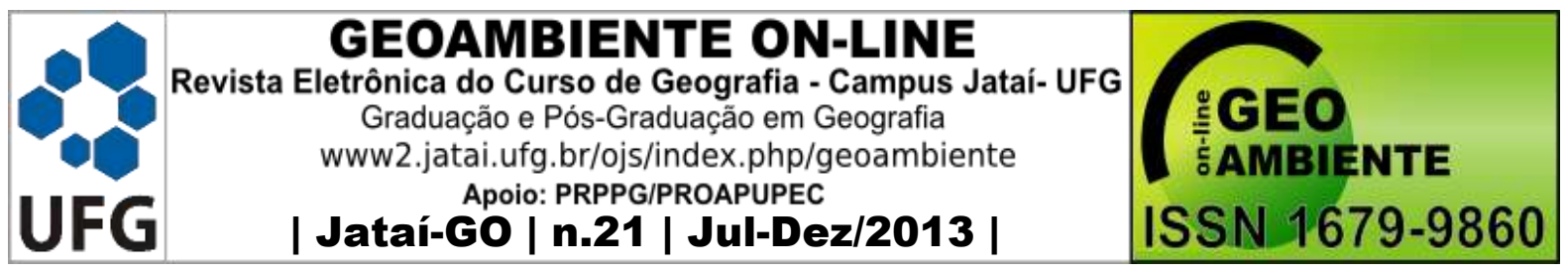

Já se fazem razoavelmente claros alguns dos princípios subjacentes quando alguém hoje em dia menciona o termo meio técnico. Obviamente, há possibilidade de haver outras leituras e compreensões, porém, como vimos, não há como fugir muito da fonte aqui mencionada. Vimos minimamente que meio se relaciona com outros conceitos e também como se relaciona. Vimos, também, como um crescente processo de artificialização vai paulatinamente modificando seu conteúdo e como esse modificar é periodizado terminologicamente por Santos. No entanto, para atendermos o escopo de compreensão do meio técnico, faltaria ainda uma única consideração provinda da questão: Como o meio técnico pode aspirar ser um ente analítico e explicativo da sociedade com autonomia frente às ciências humanas? Questão essa que em outras palavras se exprime: Qual a legitimidade da ciência geográfica segundo essa concepção teórico-metodológica? A sua resposta necessitará, mais uma vez, da boa utilização do conceito de meio técnico.

Declaradamente inspirado pela filosofia de Jean-Paul Sartre (1905-1980), Milton Santos deixou implícito em seus escritos uma concepção de homem como ser projetivo, como o único ser na natureza que age segundo um projeto de ordem existencial. Agindo, portanto, num mundo anterior a ele. Atuando como um ser fincado no mundo. Projetando-se e, de certa forma, realizando um ato de ver-se agindo no futuro. Todavia, sabemos, nem todos os projetos se realizam do modo como foram pensados. Pois, se sempre assim o fossem, habitaríamos um mundo onírico, sem resistência; um mundo ficcional onde não viveríamos, mas atuaríamos num filme do qual também estranhamente estaríamos sentados na cadeira do diretor. E o que se encontra justamente entre a projeção e o ato é o meio ao qual vivemos, ele é a real resistência. Assim, ao longo da história, os seres humanos o enfrentaram e foram, pouco a pouco, por tentativa e erro, modificando-o como objetivavam em seus projetos. Porém, seus projetos, em concomitância, eram também modificados por conta da resistência gerada pelo meio. Os humanos foram geografando um mundo onde o resultado era reconhecido como fruto de um projeto e de uma ação feita por eles. E, como resultado, os objetos que os envolviam possuíam explicações históricas e geográficas. Ou seja, sabiam dos objetos de seu meio os porquês que haviam surgido e o porquês que estavam onde estavam. Porém, como vimos, para Santos, a inauguração do meio técnico acarretou, dentre as suas novidades, um início do estranhamento, que hoje se dá a níveis supremos, em relação aos objetos dispostos no meio. A maquinização do território instalou próteses cujas explicações foram reservadas hoje para poucos técnicos, que por suas vezes, sabem até explicar seu 


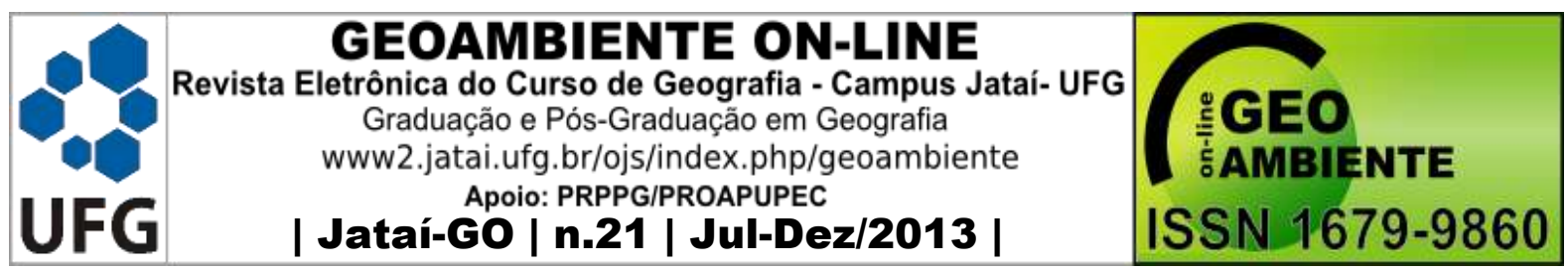

funcionamento, mas não têm o real conhecimento sobre os motivos sociais de seus usos. Nessa constante artificialização do meio, junto ao espraiamento territorial da divisão do trabalho, formas foram surgindo e sendo substituídas na paisagem já sem explicação. Exigindo, ainda, ações específicas para suas melhores realizações. É dessa maneira que:

\begin{abstract}
As ações são cada vez mais precisas e, também, mais cegas, porque obedientes a um projeto alheio. Em virtude do papel dos objetos técnicos, a ação é cada vez mais racional, mas a sua razão é, frequentemente, uma razão técnica. Dentro de uma ordem pragmática, a racionalidade do que é fim para outrem acaba sendo a racionalidade do meio e não do sujeito (SANTOS, 2004, p. 81).
\end{abstract}

Mas, então, segundo esta passagem, os objetos estariam agindo? O meio estaria agindo? Seria isso possível? Como bem se sabe, a ação é propriedade de um sujeito e, portando, não poderíamos de forma alguma considerar um objeto como um ser agente. No entanto, se de fato queremos entender os processos da realidade, não devemos nos contentar com apenas as construções linguísticas vigentes. Muito das vezes um raciocínio complexo sofre para conseguir ser expresso pelo ranço de lógicas mais simples que se assentaram semanticamente nos discursos. Neste caso, dizer que os objetos de maneira alguma podem agir - dando-se por satisfeito com a réplica - é no mínimo preocupante para a legitimação do discurso geográfico. Afinal, seguindo este raciocínio simplório, a geografia de um lugar não participaria das ações presentes nele; o que acarretaria uma pergunta cuja resposta, podemos facilmente prever, seria inevitavelmente desoladora: Para que então estudar geografia? Se atentarmos bem para isso, certamente iremos ver o valor presente na passagem seguinte:

\footnotetext{
Objetos não agem, mas, sobretudo no período histórico atual, podem nascer predestinados a um certo tipo de ações, a cuja plena eficácia se tornam indispensáveis. São as ações que, em última análise, definem os objetos, dando-lhes um sentido. Mas hoje, os objetos "valorizam" diferentemente as ações em virtude de um conteúdo técnico. Assim, considerar as ações separadamente ou os objetos separadamente não dá conta da sua realidade histórica. Uma geografia social deve encarar, de um modo uno, isto é, não-separado, objetos e ações "agindo" em concerto (ibidem, p. 86).
}

Antes de tudo, é interessante vermos que os limites da linguagem estão presentes nos termos postos entre aspas "valorizam" e "agindo". Mas o que de fato devemos nos ater, é a argumentação a favor da importância de se considerar o meio ao qual se dá a ação. Não é preciso lembrar que vivemos num mundo onde o meio é cada vez mais artificializado, ou seja, feito por artifícios produzidos por sujeitos. Sujeitos plenos em intenções. Intenções que se cristalizam em formas de objetos que aceitam as ações de maneira diferenciada, seletiva. 


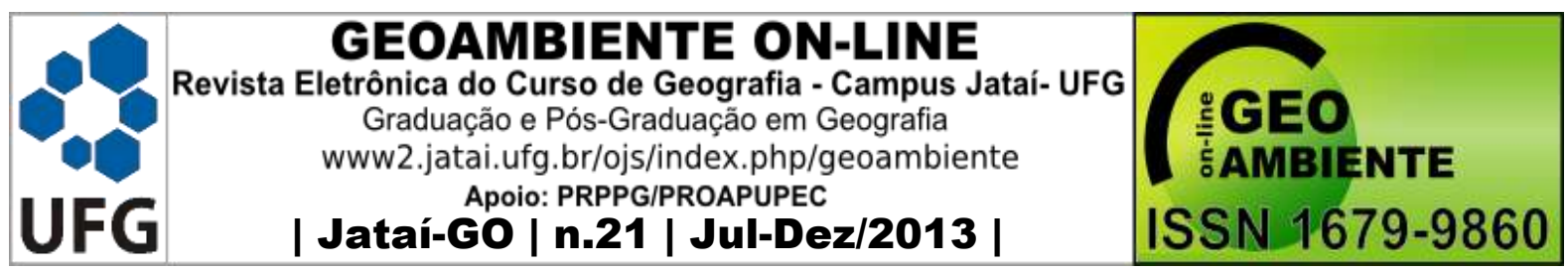

Assim, o trabalho morto materializado no meio ergue-se como dado não passivo na sociedade. Justamente porque "[...] a práxis inscrita no instrumento pelo trabalho anterior define a priori as condutas [...]" (SARTRE apud SANTOS, 2004, p. 299), o meio entendido como produto social faz-se, então, como uma entidade explicativa das sociedades. Pois, a "[...] cada momento, em última análise, a sociedade está agindo sobre ela própria, e jamais sobre a materialidade exclusivamente" (SANTOS, 2004, p. 110). Essa idéia, transposta sob certas modificações por Santos à Geografia, é aquela mesma lançada por Sartre em seu Crítica da Razão Dialética; afinal, nas palavras de Santos, “[...] podemos dizer que o espaço, pelas suas formas geográficas materiais, é a expressão mais acabada do prático-inerte" (ibidem, p. 317).

\section{Considerações finais}

Dentro do exposto, vimos que se o meio, constituído inegavelmente de uma ordem geográfica, ganhando cada vez mais intencionalidade, seleciona ações, então, também se faz como possibilidade de resposta aos questionamentos contemporâneos acerca de uma das facetas do fenômeno humano. Este ser, explicado enquanto agrupado em sociedade, seguidor de uma cultura, determinado por ordens políticas e econômicas, fruto de um enredo histórico, possuidor de uma biologia e psicologia única; também pode ser desvelado como um resultado sempre inacabado das relações necessárias, mediadas pela técnica, com o meio geográfico constituído por determinadas formas e conteúdos. Assim é, para Milton Santos, que a Geografia, enquanto disciplina acadêmica, ganharia um importante quinhão de terra nas explicações da ordem humana, bem como, no papel de reconhecimento das inescapáveis determinações tecno-mesológicas que as relações sociais contemporâneas se encontram.

\section{Referências bibliográficas}

GERALDINO, Carlos F. G. O conceito de meio na Geografia. Dissertação (Mestrado em Geografia Humana) - Departamento de Geografia, Universidade de São Paulo, São Paulo, 2010 .

GRIMM, Flávia. Contribuições teóricas do geógrafo Milton Santos para pensar o período tecnológico. Anais do II ENHPG, São Paulo, 2007.

SANTOS, Milton. Por uma geografia nova. São Paulo: Hucitec, 1978. Técnica, espaço, tempo. $4^{\mathrm{a}}$ ed. São Paulo: Hucitec, 1998. 


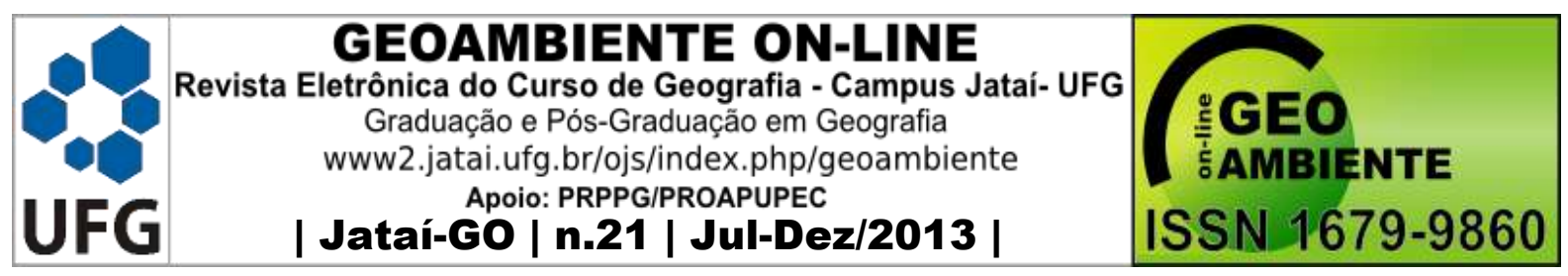

Modo de produção técnico-científico e diferenciação espacial. Revista Território. Rio de Janeiro, ano IV, nº 6, 1999.

Saúde e ambiente no processo de desenvolvimento. Ciênc. Saúde coletiva, Rio de Janeiro, v. 8, n. 1, 2003.

. A natureza do espaço. $4^{\mathrm{a}}$ ed. São Paulo: Edusp, 2004.

SARTRE, Jean-Paul. Crítica da razão dialética. Trad. Guilherme João de Freitas Teixeira e apresentação da edição brasileira por Gerd Bornheim. Rio de Janeiro: DP\&A, 2002.

VIDAL DE LA BLACHE, Paul. Princípios de geografia humana. Trad. Fernando Martins. Lisboa: Cosmos, 1946. 